\title{
Stability Analysis of High-Pile and high-pier Considering Initial Pier Deviation
}

\author{
Zhu Mei-liang ${ }^{1}$, Zhang Li-qing ${ }^{2,3,}{ }^{*}, \mathrm{Ma} \mathrm{Ye}^{2}$ and Jiang Shun-kun ${ }^{2}$ \\ ${ }^{1}$ Hangzhou Qianhuang Expressway Co., Ltd., Hangzhou 310030, China \\ ${ }^{2}$ Research Institute of Highway, Ministry of Transport, Beijing 100088, China \\ ${ }^{3}$ China-Road Transportation Verification \& Inspection Hi-Tech Co.,Ltd., Beijing 100088, China
}

\begin{abstract}
Based on the high-pile and high-pier bridge of Qianhuang Expressway, eigenvalue buckling analysis is carried out by establishing three-dimensional finite element models of three different bridge types and high-pier types, and the corresponding structural nonlinear buckling loads under different initial pier deviations are calculated. The calculation results show that the nonlinear buckling loads of three high-pier types are less than elastic buckling loads. The stability of column high-pile and high-pier of continuous bridge is better than that of simple supported bridge, and the stability of plate high-pier is better than that of other two high-piers. In addition, the corresponding buckling load decreases with the increase of the initial horizontal displacement, indicating that the pier top offset of the high-pile and high-pier bridge is not conducive to the stability of the structure.
\end{abstract}

\section{Introduction}

Structural damage can generally be divided into two basic forms: strength failure and instability failure ${ }^{[1,2]}$. With the development of Chinese economy, many newly built bridges need to cross deep valleys and piers are becoming taller and more flexible. The reduction of high-pier structure stiffness makes its stability problems become increasingly prominent, and the influencing factors of the stability of high-pier structure become the focus of research ${ }^{[3]}$. By comparing the stability of single leg box thin-walled pier and double leg rectangular thin-walled pier, Guo Lanying ${ }^{[4]}$ believed that single leg box thinwalled pier has better linear elastic stability. Chai Jinling et al. ${ }^{[5]}$ found that the nonlinear stability of the thin-walled high pier structure increased approximately linearly with the increase of concrete strength, and showed a nonlinear growth trend with the increase of the amount of ordinary reinforcement. Wang Kaihua et al. ${ }^{[6]}$ found that the stability of high pier in the completion stage is higher than that in the construction stage, and the stability of single pier is higher than that of double pier with the same crosssectional dimensions. Through FEM analysis, Du Jinsheng et al. [7] analyzed the geometric nonlinear stability of thin-walled high pier with different construction defects and concluded that the greater the initial construction defect depth of pier and the closer the defect location from the bottom of pier, the lower the stability of pier.

Deflection of the pier top of high-pier bridge has a great impact on the structural performance and its safety ${ }^{[8]}$. How the deflection of the pier top affects the stability of the high-pier in the operation stage of bridge needs further attention. This paper is based on the study of highpile and high-pier bridge of Chun'an section of Zhejiang Province (hereinafter referred to as "Chun'an section of Qianhuang expressway") of Liyang Ningde national expressway. By establishing three-dimensional finite element models of three different bridge types and high pier types, the stability of the pier including the eigenvalue buckling analysis and the nonlinear buckling analysis after the pier top being deviated is compared and analysed to study the influence to pier stability due to the deviation of pier top ${ }^{[9]}$.

\section{Project profile}

The Chun'an section of Qianhuang Expressway crosses the Qiandao Lake scenic spot. The bridge needs to cross deep ditch and lake reservoir, and there are a large number of high pile and high pier bridges located in deep water area. In this paper, three representative piers are selected, which are the No.3 pier on the right side of miaojiawu No.1 Bridge, No.5 pier on the right side of Baizhao bridge and No.8 pier on the right side of Lingfang line bridge. Superstructure of selected bridges are fabricated prestressed concrete $\mathrm{T}$ beams. The design vehicle load grade is highway grade I. The substructures are double column circular pier, three column circular pier and slab pier respectively, and all with bored pile foundation. The basic information of bridge is shown in Table 1.

\footnotetext{
* Corresponding author: 34320409@qq.com 


\section{FEM Model}

Figure 2 shows the high-pile and high-pier model established by ANSYS. SOLID65 three-dimensional element is used to establish the overall model of pier structure, and real constant property is used to simulate the reinforcement embedded in plain concrete. The reinforcement in the concrete is considered to be uniformly "dispersed" in the element. The distribution density of reinforcement in each element is the same. The density of reinforcement is expressed by volume reinforcement ratio (reinforcement volume/unit volume). Each 3D solid element can define the reinforcement of three directions respectively and the corresponding reinforcement ratio and reinforcement material properties of reinforcement in each direction are specified respectively. In the modeling coordinate system, $\mathrm{Z}$ direction is the vertical direction, $\mathrm{Y}$ direction is the path direction, and $\mathrm{X}$ direction is the horizontal direction.

Soil spring is used to simulate the pile-soil interaction in the part of pile foundation in soil. combin 14 element is used to simulate soil spring. The constraint of the soil to the pile is simulated as a 3D axial spring horizontally placed along the radial direction of the pile. The spring length is $0.7 \mathrm{~m}$. One end of the spring is the element node on the outer surface of the pile, and the other end is a fixed bearing. The spring stiffness of different soil layers is achieved by changing the elastic modulus of the spring. The calculation method of spring stiffness refers to the method provided in appendix $\mathrm{P}$ of the Specifications for Design of Foundation of Highway Bridges and Culverts (JTG 3363-2019) ${ }^{[10]}$. Firstly, according to the geological conditions and calculation accuracy requirements, the pile is divided into several parts. Then determine the calculating width $\mathrm{B} 1$ of each section pile, the horizontal foundation resistance coefficient $\mathrm{Cz}$ and the length $\mathrm{L}$ of section pile, and the product of the above three values is the horizontal stiffness of the spring.

According to the vertical load-displacement curve, the vertical load has an extreme point or tend to a certain critical value with the gradual increase of displacement. This critical value will be deemed as the stability bearing capacity of pier.

Table 1. Basic information of bridge.

\begin{tabular}{|c|c|c|c|c|c|c|}
\hline Bridge name & Pier No. & Superstructure & Pier type & $\begin{array}{c}\text { Pier } \\
\text { height }(\mathrm{m})\end{array}$ & $\begin{array}{c}\text { Pile } \\
\text { length }(\mathrm{m})\end{array}$ & $\begin{array}{c}\text { Pile length } \\
\text { above river } \\
\text { bed }(\mathrm{m})\end{array}$ \\
\hline $\begin{array}{c}\text { miaojiawu No.1 } \\
\text { Bridge }\end{array}$ & $\begin{array}{l}\text { No. } 3 \text { pier on } \\
\text { the right side }\end{array}$ & $\begin{array}{c}\text { 5x30msimply-supported-to- } \\
\text { continuous Prestressed } \\
\text { concrete T-beam }\end{array}$ & $\begin{array}{c}\text { double } \\
\text { column } \\
\text { circular pier }\end{array}$ & 23.13 & 27.50 & 6.5 \\
\hline Baizhao bridge & $\begin{array}{l}\text { No. } 5 \text { pier on } \\
\text { the right side }\end{array}$ & $\begin{array}{c}3 \times 40 m \text { Continuous Deck } \\
\text { Simple-supported Prestressed } \\
\text { concrete T-beam }\end{array}$ & $\begin{array}{l}\text { three } \\
\text { column } \\
\text { circular pier }\end{array}$ & 28.65 & 42.00 & 18.2 \\
\hline $\begin{array}{l}\text { Lingfang line } \\
\text { bridge }\end{array}$ & $\begin{array}{l}\text { No.8 pier on } \\
\text { the left side }\end{array}$ & $\begin{array}{l}\text { 4x30msimply-supported-to- } \\
\text { continuous Prestressed } \\
\text { concrete T-beam }\end{array}$ & slab pier & 24.46 & 29.00 & 9.5 \\
\hline
\end{tabular}

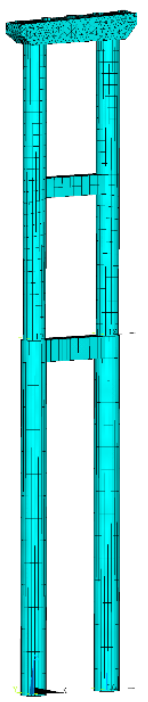

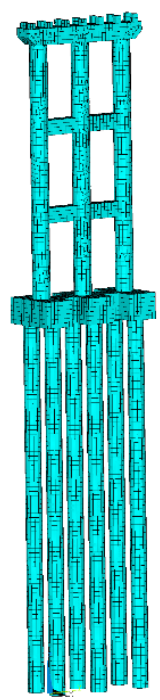

a) No.3 pier on the right side of miaojiawu No.1 Bridge b) No.5 pier on the right side of Baizhao bridge

c) No.8 pier on the left side of Lingfang line bridge

Fig. 1. FEM Model of the high-pile and high-pier.

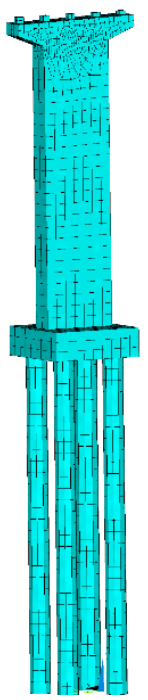




\section{Stability analysis results}

\subsection{Stability analysis of No.3 pier on the right side of miaojiawu No.1 Bridge}

Subspace iteration method is used for buckling analysis, and the first-order buckling load is obtained as $96288.9 \mathrm{kN}$, and the maximum displacement of the pier top corresponding to the first-order in-plane instability modal is $0.6534 \mathrm{~m}$.

Taking the first-order in-plane instability modal as reference for the actual initial defect application, and apply 1 time, 1.5 times, 2 times and 2.5 times of the initial displacement on the pier top in $\mathrm{x}$ direction as the initial displacement defect of the pier top. The load displacement curve of the pier top node is obtained through nonlinear analysis as shown in Figure 2.

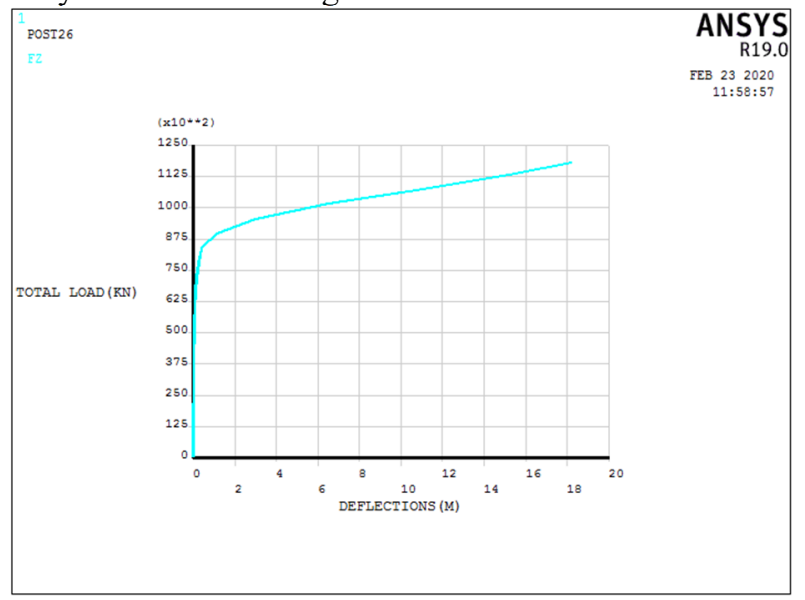

a) Load-displacement curve while applying 1 time of the initial displacement on the pier top as the initial displacement defect

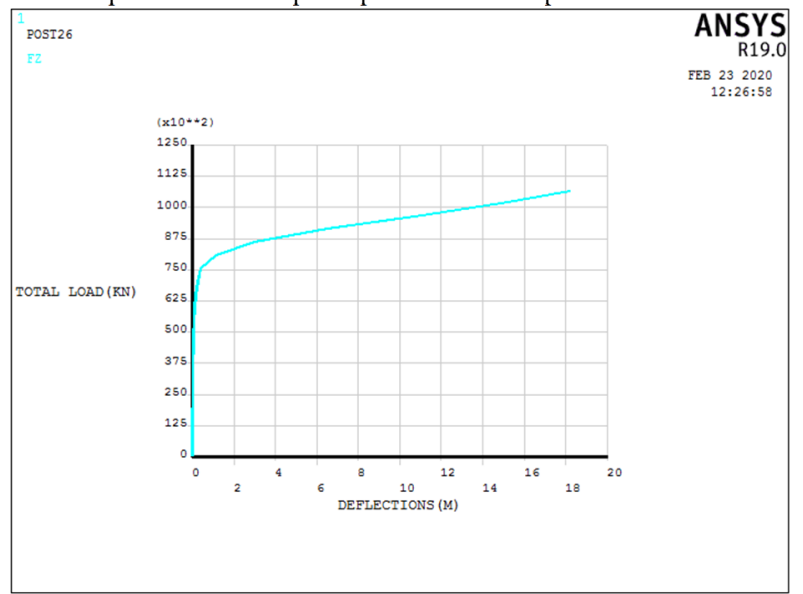

b) Load-displacement curve while applying 1.5 times of the initial displacement on the pier top as the initial displacement defect

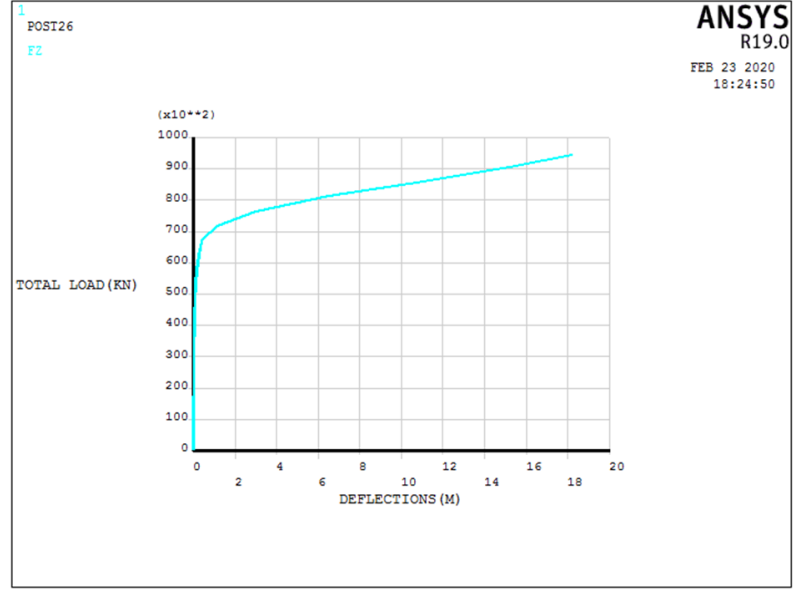

c) Load-displacement curve while applying 2 times of the initial displacement on the pier top as the initial displacement defect

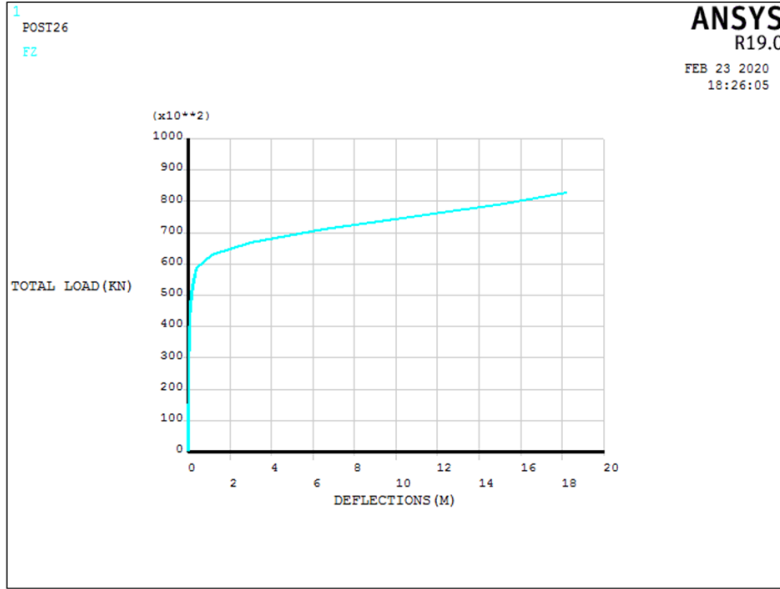

d) Load-displacement curve while applying 2.5 times of the initial displacement on the pier top as the initial displacement defect

Fig. 2. Load-displacement curve with initial displacement defect of No.3 pier on the right side of miaojiawu No.1 Bridge.

The load corresponding to the inflection point of the load displacement curve in the figure above is about $87000 \mathrm{kN}, 76000 \mathrm{kN}, 68000 \mathrm{kN}$ and $61000 \mathrm{kN}$ respectively, which is the corresponding nonlinear buckling load of the structure.

\subsection{Stability analysis of No.5 pier on the right side of Baizhao bridge}

Subspace iteration method is used for buckling analysis, and the first-order buckling load is obtained as $165934.1 \mathrm{kN}$, and the maximum displacement of the pier top corresponding to the first-order in-plane instability modal is $0.4089 \mathrm{~m}$.

Taking the first-order in-plane instability modal as reference for the actual initial defect application, and apply 1 time, 1.5 times, 2 times and 2.5 times of the initial displacement on the pier top in $\mathrm{x}$ direction as the initial displacement defect of the pier top. The load-displacement curve of the pier top node is obtained through nonlinear analysis as shown in Figure 3. 


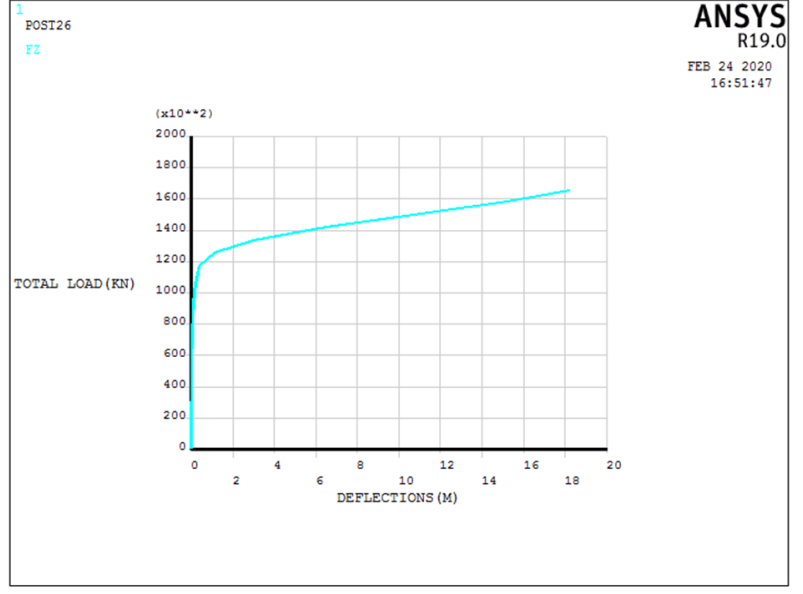

a) Load-displacement curve while applying 1 time of the initial displacement on the pier top as the initial displacement defect

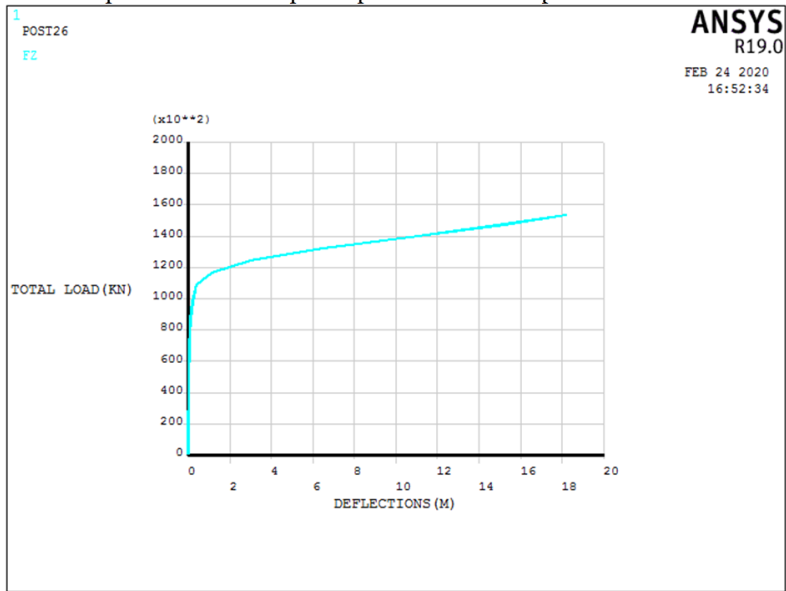

b) Load-displacement curve while applying 1.5 times of the initial displacement on the pier top as the initial displacement defect

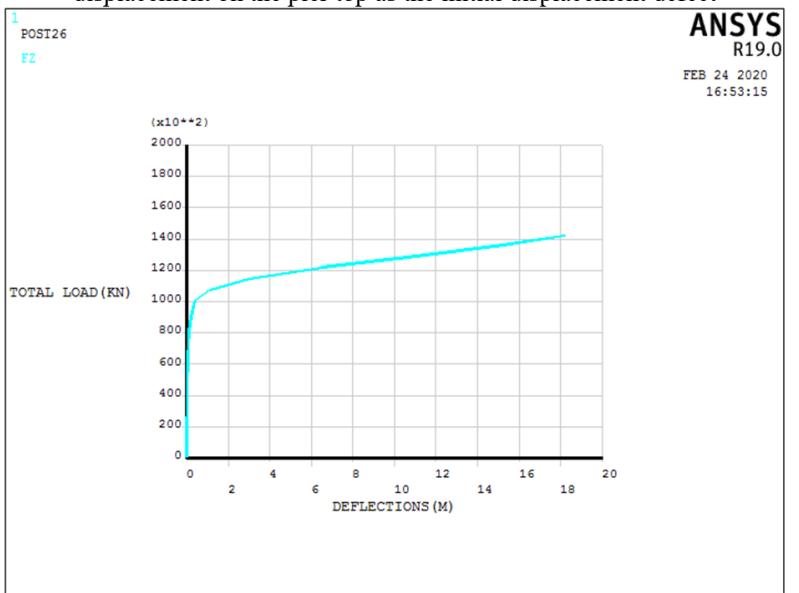

c) Load-displacement curve while applying 2 times of the initial displacement on the pier top as the initial displacement defect

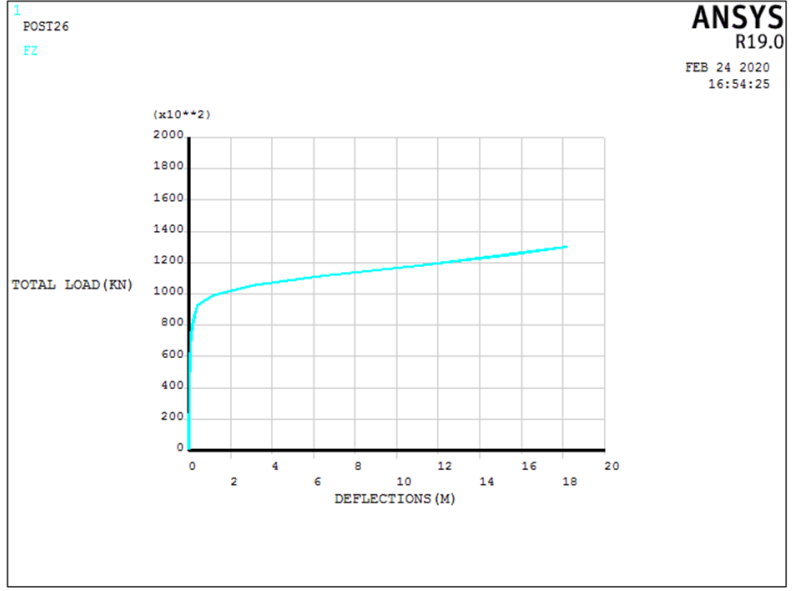

d) Load-displacement curve while applying 2.5 times of the initial displacement on the pier top as the initial displacement defect

Fig. 3. Load-displacement curve with initial displacement defect of No.5 pier on the right side of Baizhao bridge.

The load corresponding to the inflection point of the load displacement curve in the figure above is about $119000 \mathrm{kN}, 111000 \mathrm{kN}, 106000 \mathrm{kN}$ and $92000 \mathrm{kN}$ respectively, which is the corresponding nonlinear buckling load of the structure.

\subsection{Stability analysis of No.8 pier on the left side of Lingfang line bridge}

Subspace iteration method is used for buckling analysis, and the first-order buckling load is obtained as $403640.2 \mathrm{kN}$, and the maximum displacement of the pier top corresponding to the first-order in-plane instability modal is $0.1606 \mathrm{~m}$.

Taking the first-order in-plane instability modal as reference for the actual initial defect application, and apply 1 time, 1.5 times, 2 times and 2.5 times of the initial displacement on the pier top in $\mathrm{x}$ direction as the initial displacement defect of the pier top. The load-displacement curve of the pier top node is obtained through nonlinear analysis as shown in Figure 4.

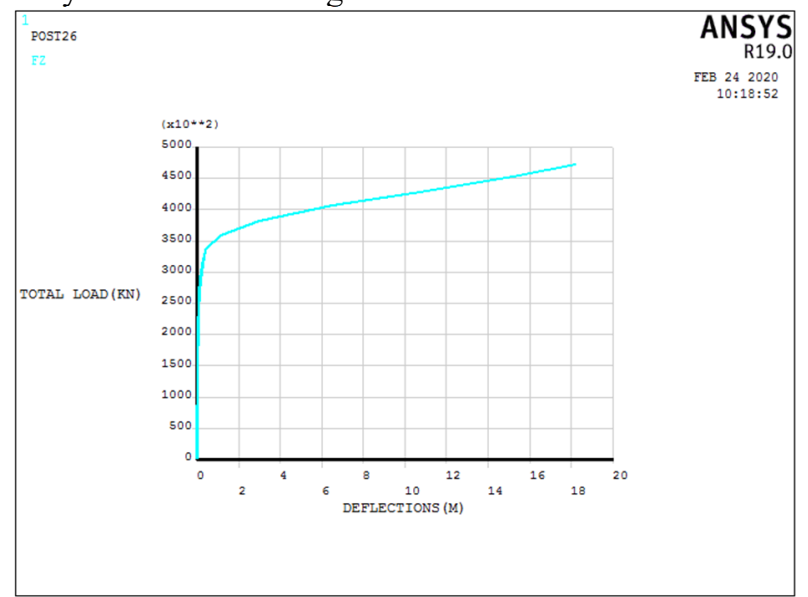

a) Load-displacement curve while applying 1 time of the initia displacement on the pier top as the initial displacement defect 


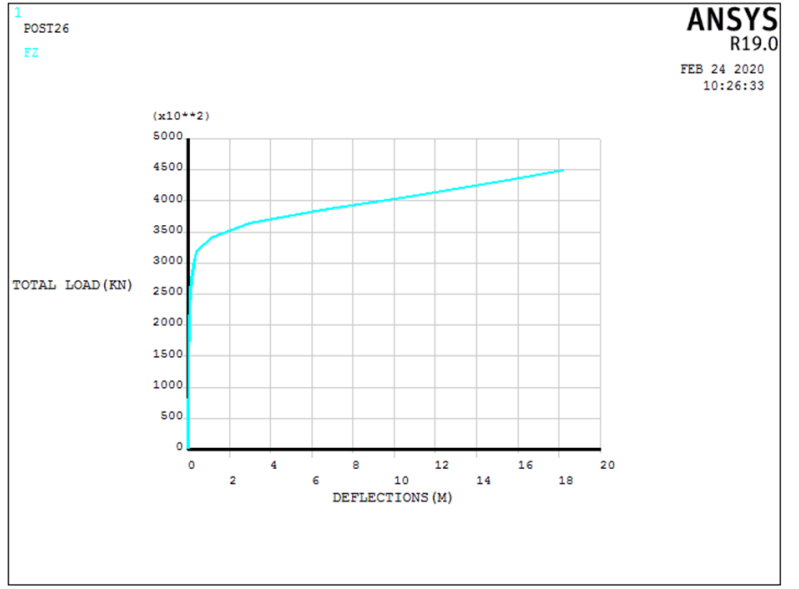

b) Load-displacement curve while applying 1.5 times of the initial displacement on the pier top as the initial displacement defect

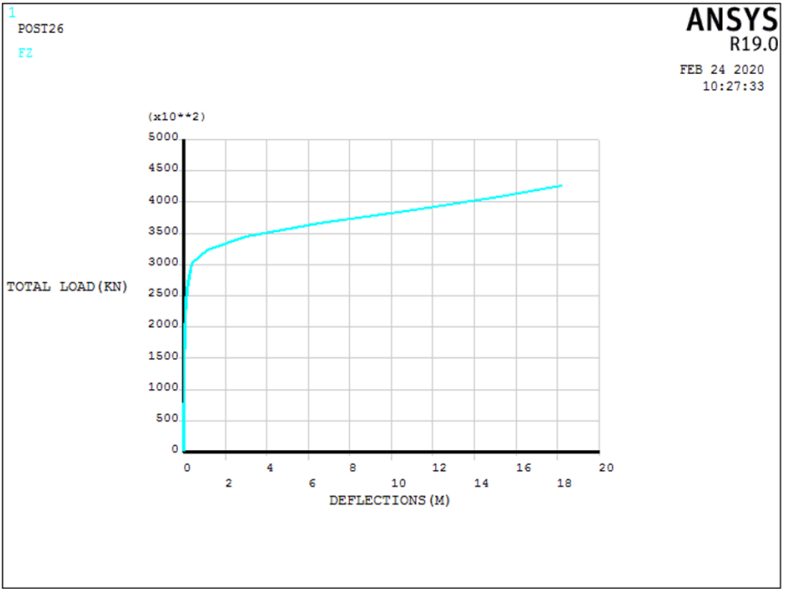

c) Load-displacement curve while applying 2 times of the initial displacement on the pier top as the initial displacement defect

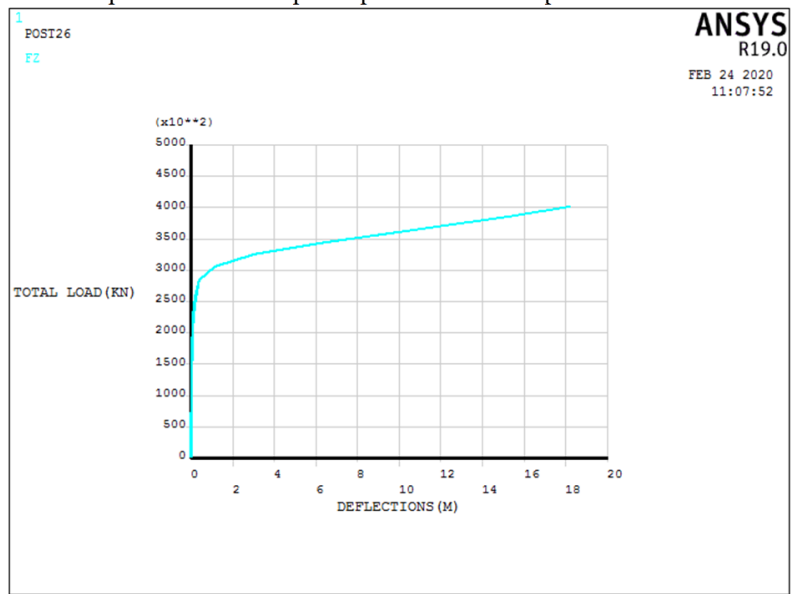

d) Load-displacement curve while applying 2.5 times of the initial displacement on the pier top as the initial displacement defect

Fig. 4. Load-displacement curve with initial displacement defect of No.5 pier on the right side of Baizhao bridge.

The load corresponding to the inflection point of the load displacement curve in the figure above is about $342000 \mathrm{kN}, 325000 \mathrm{kN}, 310000 \mathrm{kN}$ and $290000 \mathrm{kN}$ respectively, which is the corresponding nonlinear buckling load of the structure.

\subsection{Comparison and analysis of the calculation result}

The critical buckling force of the structure obtained by eigenvalue buckling analysis is usually larger, and the predicted value is usually greater than the actual critical buckling force. From the eigenvalue buckling analysis and nonlinear buckling analysis of the above three high-pier and high-pile bridges, it can be seen that the nonlinear buckling load values obtained with initial displacement defect is less than the elastic buckling load, and the corresponding buckling load decreases with the increase of the initial displacement defect, which shows that pier top deflection of high-pile and high-pier bridge is not favourable to the stability of the structure.

Table 2. Calculation result of the stability factor.

\begin{tabular}{cccc}
\hline $\begin{array}{c}\text { No.3 pier on } \\
\text { fability } \\
\text { the right side } \\
\text { of miaojiawu } \\
\text { No.1 Bridge }\end{array}$ & $\begin{array}{c}\text { No.5 pier on } \\
\text { the right } \\
\text { side of } \\
\text { Baizhao } \\
\text { bridge }\end{array}$ & $\begin{array}{c}\text { No.8 pier on } \\
\text { the left side } \\
\text { of Lingfang } \\
\text { line bridge }\end{array}$ \\
\hline $\mathrm{n}_{\mathrm{cr}}$ & 19.5 & 13.2 & 44.6 \\
$\mathrm{n}_{\mathrm{cr} 1^{\prime}}$ & 17.6 & 9.5 & 37.8 \\
$\mathrm{n}_{\mathrm{cr} 1.5^{\prime}}$ & 15.4 & 8.8 & 35.9 \\
$\mathrm{n}_{\mathrm{cr} 2}{ }^{\prime}$ & 13.8 & 8.4 & 34.2 \\
$\mathrm{n}_{\mathrm{cr} 2.5^{\prime}}$ & 12.4 & 7.3 & 32.0 \\
\hline
\end{tabular}

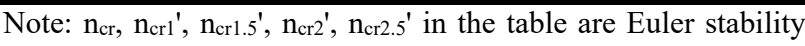
coefficient and nonlinear stability coefficient of applying 1 times, 1.5 times, 2 times, and 2.5 times displacement defect on pier top in $\mathrm{x}$ direction.

The calculation results of Euler stability coefficient and nonlinear stability coefficient of three high-pier bridges under different conditions are shown in Table 2. According to the calculation results, the Euler stability coefficients are all greater than 4 , and the nonlinear stability coefficients are all greater than 2 , and the stability and safety performance of the structure is guaranteed. For high-pile and high-pier bridge, the stability of continuous beam bridge is better than that of simply supported bridge, and the slab pier has the best stability.

With the increase of initial displacement defects, the corresponding buckling load decreases, and the deflection of pier top of high-pile and high-pier bridge in bridge operation period is not conducive to the stability of the structure.

\section{Conclusion}

Based on an example of high-pile and high-pier bridge in Chun'an section of Qianhuang expressway, the stability of high pier of different bridge types and pier body types are compared and analysed in this paper and draws the following conclusions.

(1) The Euler stability coefficients of the high piers of the three bridges are all greater than 4 , and the nonlinear stability coefficients are all greater than 2. The stability and safety performance of the structure meets the requirements.

(2) The buckling load and stability factor of the bridge pier decrease with the increase of the pier 
top deflection, and the variation of the two are nonlinear correlation.

(3) For column-type high-pile and high-pier bridge, the stability of continuous beam bridge is better than that of simply supported bridge, and the stability of slab-type high pier is better than that of column-type high pier.

(4) The deviation of pier top of high-pier bridge is not favourable to the stability of the structure, so attention should be paid to the deviation of high pier when the bridge is in operation.

\section{Acknowledgements}

The research work presented herein is sponsored by Scientific Research Project of Zhejiang Provincial Department of Transportation (2020-GCKY-01).

\section{References}

1. C.Y. Li, Study on mechanical behavior of flexible high pier with complex boundary (2017)

2. Y. Yang, L.M. Zhou, Y.J. Zhou, Curved bridge and high pier (2011)

3. J.F. Zhao, W. Wang, X. Zhang, Research status and Prospect of mechanical properties of bridge high pier structure, Journal of Zhejiang communications Polytechnic, 21, 02 (2020)

4. L.Y. Guo, Comparative study on stability of single leg box thin wall high pier and double leg rectangular thin wall high pier, Highway transportation technology, 30(9), 87-93(2013)

5. J.L. Jin, Z.Q. Feng, Y. Wang, G.B. Tang, Influence of reinforced concrete materials on nonlinear stability of thin walled high pier structure, Highway engineering, 39(03), 154-157(2014)

6. K. H. Wang, Z. C. Liu, Pier type selection and stability analysis of Long Span High Pier Continuous Rigid Frame Bridge, Low temperature building technology, 41(06), 134-137(2019)

7. J. S. Du, J.L. Kang, X. F. Luo, Stability analysis of high pier considering construction defects and initial eccentricity, Engineering mechanics, 28(S1), 115$118+124(2011)$

8. K. S. Jiang, L. Q. Zhang, H.J. Lou, Research and Analysis on horizontal displacement calculation and limit control of high pier of bridge, Highway engineering, 1(2020)

9. K. S. Jiang, Structural performance analysis and limit structure research of high pile and high pier of deep water bridge(2020)

10. Specifications for Design of Foundation of Highway Bridges and Culverts (2019) 